\title{
La contre-culture au Québec, sous la direction de Karim LAROSE et Frédéric RONDEAU
}

\section{Emanuela Cacchioli}

\section{OpenEdition}

\section{Journals}

\section{Edizione digitale}

URL: https://journals.openedition.org/studifrancesi/12267

DOI: 10.4000/studifrancesi. 12267

ISSN: 2421-5856

\section{Editore}

Rosenberg \& Sellier

\section{Edizione cartacea}

Data di pubblicazione: 1 avril 2018

Paginazione: 180

ISSN: 0039-2944

Notizia bibliografica digitale

Emanuela Cacchioli, «La contre-culture au Québec, sous la direction de Karim LaRose et Frédéric RONDEAU», Studi Francesi [Online], 184 (LXII | I) | 2018, online dal 04 juillet 2018, consultato il 17 novembre 2021. URL: http://journals.openedition.org/studifrancesi/12267 ; DOI: https://doi.org/ 10.4000/studifrancesi.12267

Questo documento è stato generato automaticamente il 17 novembre 2021.

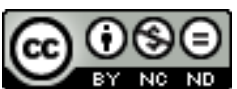

Studi Francesi è distribuita con Licenza Creative Commons Attribuzione - Non commerciale - Non opere derivate 4.0 Internazionale. 


\title{
La contre-culture au Québec, sous la direction de Karim LAROSE et Frédéric RONDEAU
}

\author{
Emanuela Cacchioli
}

\section{NOTIZIA}

La contre-culture au Québec, sous la direction de Karim LAROSE et Frédéric RONDEAU, Montréal, Les Presses de l'Université de Montréal, 2016, 530 pp.

1 Un viaggio nella controcultura canadese, nelle sue diverse manifestazioni, anche contraddittorie, è quello che ci propongono Karim LAROSE e Frédéric RONDEAU. I curatori del volume hanno riunito contributi su aspetti diversi di quel «movimento» che si diffonde negli Stati Uniti e in Europa per circa un decennio tra gli anni Sessanta e Settanta del secolo scorso. Abbiamo messo la parola movimento tra virgolette perché, come bene emerge dai vari articoli, non si tratta di un fenomeno unitario. Si possono rintracciare linee convergenti perché una fetta della popolazione avverte la necessità di opporsi all'ideologia dominante, alla cultura di massa, all'omologazione voluta dalla società industriale. Tuttavia, questa ricerca di emancipazione sociale segue strade diverse anche a seconda della personalità dell'autore e dell'ambito di applicazione di tale fermento. La prospettiva di questo volume è resa particolarmente interessante dal fatto che cerca di dare una visione realistica e variegata delle manifestazioni della controcultura nel complesso contesto geografico e sociale del Québec. Un obiettivo ambizioso, in larga misura realizzato, anche grazie ai contributi di numerosi specialisti che si occupano di musica, teatro, letteratura, cinema, arti figurative e carta stampata.

2 La prima sezione è dedicata appunto alla musica e in particolare al jazz e al rock. Éric FILLION ripercorre la diffusione del «jazz libre» e del suo influsso nelle pratiche culturali, intese come studio dei discorsi e dei luoghi artistici di maggior interesse per l'epoca. Il rock come sintomo del cambiamento sociale e del rifiuto della gerarchia è il focus scelto 
da Jean-Pierre SIROIS-TRAHAN, che compie uno studio completo sulle varie forme di rock in relazione all'evoluzione storico-sociale della controcultura. Marie-Thérèse LEFEBVRE, dal canto suo, sostiene che la musica attuale è il risultato delle sperimentazioni condotte negli anni Sessanta e Settanta proprio a partire dalla necessità di sovvertire le gerarchie sociali e di uscire dai quadri istituzionali. Su tutte spiccano l'improvvisazione e la ricerca dell'intertestualità. Dall'ambito cinematografico, ci vengono forniti due studi di caso che vogliono essere una riflessione sulla vita quotidiana dell'epoca. Germain LACASSE e Sacha LEBEL esaminano la liberazione sessuale associata alla miseria e alla violenza che ritroviamo nelle visioni grottesche dei film di Pierre Harel. MarcAndré ROBERT, invece, analizza le condizioni di produzione e la ricezione del pubblico, riferite nello specifico alla cinematografia dei fratelli Gagné. Per quanto riguarda la letteratura, Frédéric RONDEAU ci offre una prima panoramica sulla produzione romanzesca di quegli anni. Secondo il critico emerge una profonda inquietudine da parte degli autori che avvertono poca fiducia nell'avvenire e un sentimento di estraneità di fronte al mondo circostante. In poesia, riscontriamo un rifiuto radicale dell'ordine anche a livello discorsivo, come accade nei componimenti del poeta Josée Yvon. È quanto leggiamo nel contributo di Valérie MAILHOT. Simon-Pier LABELLE-HOGUE, invece, sceglie un approccio comparato per rendere conto dell'eterogeneità della controcultura. A tal proposito, analizza il ricorso alla droga e all'esibizione della sessualità negli scritti di Patrick Straram e di Louis Geoffroy come esemplificazione di una «religiosità profana». Jean-Marc LARRUE traccia un'analisi ideologica ed estetica del teatro, inteso come creazione collettiva e tentativo di resistere alle forme di dominio imposte dai gruppi maggioritari e dalle istituzioni. Seguono tre contributi sull'immaginario visuale, ossia sulle arti figurative. Anithe DE CARVALHO si occupa dell'artista underground Jean-Paul Mousseau e delle scelte operate per l'allestimento della discoteca «Le Crash». Tale prospettiva permette di indagare l'«œuvre-lieu» e la relazione di supporto che si istaura con il pubblico che la frequenta. Camille ST.-CERNY GOSSELIN opta per il fumetto e ci offre una ricognizione sulle strisce pubblicate in rivista, portatrici di un'estetica propria della controcultura che fa ampio uso della satira. Sébastien DULUDE studia le opere del poeta Denis Vanier, soffermandosi in particolare sul rapporto tra l'impaginazione dei versi, la loro disposizione sulla pagina e le immagini che dialogano con i testi. L'ultima sezione è proiettata sulla sociologia. JeanPhilippe WARREN analizza il progetto editoriale del periodico Mainmise e della sua funzione sulla circolazione delle idee. Una prospettiva diversa è, invece, adottata da Marie-Andrée BERGERON sempre a proposito della stessa rivista. Secondo la studiosa, i contenuti proposti dal giornale non tengono conto delle posizioni femministe e del modo in cui viene trattato il problema dei rapporti uomo-donna. L'ultimo articolo, di Robert SCHWARTZWALD, verte sui dibattiti interni al «Front de libération homosexuel» insistendo sul fatto che nel movimento manca una visione unitaria e che vi si affermano posizioni individualiste.

Oltre ad essere particolarmente ben strutturato, il volume è arricchito di numerosi supporti visivi (immagini, fotografie, disegni, ma anche estratti di riviste e pagine di fumetti) che completano il discorso critico in modo pertinente e mostrano la trasformazione dei diversi ambiti culturali. I contributi sono curati e permettono di seguire una panoramica molto articolata che tiene conto delle diverse manifestazioni del processo di liberazione delle coscienze. Si tratta di un ottimo strumento per indagare un momento storico che ha segnato profondamente i decenni successivi. 